\title{
Skin blood flow changes, measured by laser Doppler flowmetry, in the first week after birth
}

\author{
H.E. Suichies ${ }^{a}$, C. Brouwer, J.G. Aarnoudse ${ }^{a}$, H.W. Jentink ${ }^{b}$, \\ F.F.M. de Mulb $^{b}$ and J. Greve \\ ${ }^{a}$ Department of Obstetrics and Gynaecology, University Hospital Groningen, Oostersingel 59, 9713 EZ \\ Groningen and 'Department of Applied Physics, Twente University of Technology, P.O. Box 217, 7500 \\ AE Enschede (The Netherlands)
}

(Received 16 January 1990; received 8 March 1990; accepted 14 March 1990)

\section{Summary}

Changes in forehead skin blood flow were determined in 17 healthy, term newborns, using a fiberless diode laser Doppler flow meter (Diodopp). Measurements were carried out three times on each infant, at postnatal ages of $16.8 \pm 7.4 \mathrm{~h}, 58.9$ $\pm 6.2 \mathrm{~h}$ and $121.5 \pm 14.2 \mathrm{~h}$ (mean \pm S.D.), respectively. Skin blood flow, respiration, heart rate and skin temperature were recorded simultaneously, while the newborns were asleep. During the recordings, the behavioural state of the newborns was observed and environmental temperature and humidity were kept constant. Postocclusive hyperaemia of the skin blood flow was obtained by pressing the laser Doppler probe against the skull for 30 or $60 \mathrm{~s}$. The following parameters changed significantly between the first and third measurements ( $t$-test for paired samples): the basal skin blood flow during active and quiet sleep decreased, the average decrease being $29.4 \%(P=0.002)$ and $25.9 \%(P=0.01)$, respectively; skin blood flow during postocclusive hyperaemia also changed: the time taken to reach maximum hyperaemia increased from 17.3 to $22.7 \mathrm{~s}(P=0.01)$, while the halftime recovery increased from 46.1 to $57.1 \mathrm{~s}(P=0.02)$. The changes in skin blood flow between the first and second measurements and between the second and third measurements did not reach the level of statistical significance.

skin blood flow; laser Doppler; reactive hyperaemia; newborn.

Correspondence to: J.G Aarnoudse.

0378-3782/90/\$03.50 (C) 1990 Elsevier Scientific Publishers Ireland Ltd.

Published and Printed in Ireland 
Introduction

The microcirculation of the skin is subject to considerable changes in the first few days of extrauterine life. Morphological changes were already reported in 1934 by Schwalm [161, who described the formation of an extensive papillary capillary network in the newborn's skin in the first weeks after birth. This finding was later confirmed by Perera et al. [14], who found that the development of this capillary network lasted several weeks. Initially, a disorderly capillary network is present without papillary loops or with only a few loops. Between 14 to 17 weeks after birth, the length and variability of the diameter of the capillaries has been seen to increase $[3,15,16]$.

Functional changes in the skin circulation of the newborn have been described by several authors $[1,6,19]$. How far the morphological and functional changes in the skin are represented in forehead skin blood flow changes, measured by laser Doppler flowmetry, is the subject of this study.

\section{Infants and Methods}

Seventeen healthy newborns were studied. Informed consent was obtained from the parents of the infants. The infants were born at a mean gestational age of 39.5 weeks (range 37.3-41.5 weeks) with a mean birth weight of $3888 \mathrm{~g}$ (range 2650$4840 \mathrm{~g})$. Fifteen infants were delivered spontaneously, one infant was delivered by forceps because of a lack of progress and one infant was delivered by caesarian section because of a lack of progress. All had Apgar scores of at least 7 after $1 \mathrm{~min}$ and 9 after $3 \mathrm{~min}$. None of the infants were receiving medication and none of them had clinical disturbances.

All infants were measured three times: on the first day at a mean postnatal age of $16.8 \mathrm{~h}$ (range $6.5-27 \mathrm{~h}$ ), on the third day, at a mean postnatal age of $58.9 \mathrm{~h}$ (range $49-67.5 \mathrm{~h}$ ) and on the fifth day at a mean postnatal age of $121.6 \mathrm{~h}$ (range 102$145.5 \mathrm{~h}$ ). Measurements were performed at a stable environmental temperature of $28^{\circ} \pm 0.5^{\circ} \mathrm{C}$ and a stable relative humidity of $60 \%$. Recordings were made $1-2 \mathrm{~h}$ after a feed and lasted 30-45 min, with the infants still sleeping, clothed in their cots. Skin blood flow was measured on the newborn's forehead. This place was chosen for two reasons, (1) in previous studies on newborn's skin blood flow we used the same measuring site and (2) the forehead is an easily accessible area when newborns are lying under a blanket and the skull offers the possibility of performing arterial occlusions without disturbing the newborn infant.

Skin blood flow was measured in accordance with the laser Doppler method described by others $[12,18,23]$. This method uses the frequency shift of laser light scattered by moving particles, e.g. red blood cells, to determine the velocity of the particles. Back-scattered Doppler shifted and unshifted light, mixed on a photodetector surface, produce a frequency spectrum of intensity fluctuations, which is dependent on the mean red blood cell velocity and the number of red blood cells. The laser Doppler flow value represents not a quantitative flow signal but a value consisting of the integrated velocities of all red blood cells measured under the sen- 
sor. Signal processing provides an output in volts which is proportional to the blood flow in vitro. We investigated this in a silicon model containing small channels with a diameter of $0.1 \mathrm{~mm}$. This model was covered with human epidermis and perfused by a heparinized physiological saline solution containing red blood cells. The red blood cell concentrations varied from $0.5 \%$ to $3 \%$ and the velocities ranged from 0.5 to $5 \mathrm{~mm} / \mathrm{s}$. In this model the laser Doppler flowmeter showed a linear response.

In the present study, a recently developed laser Doppler flowmeter (Diodopp) was used. The light source (Hitachi laserdiode, $5 \mathrm{~mW}$, wavelength $790 \mathrm{~nm}$ ), two detectors (Philips BPX40 photodiodes), each at a distance of $2.5 \mathrm{~mm}$ from the light source, and a Peltier effect element (Melcor), which keeps the sensor's temperature constant, are integrated in the sensor $[9,20]$. Optical fibres, sensitive to movement artefacts, are therefore not used. Signal processing between 30 and $300 \mathrm{kHz}$ provides an output in volts. The instrument does not use a linearizer, which may result in a slight underestimation of the output signal, due to multiple scattering. The skin area illuminated by the laser is estimated at between 15 and $25 \mathrm{~mm}^{2}$. The measuring depth of the sensor is, given its wavelength and the distance between light source and detector, estimated at between 1.5 and $2 \mathrm{~mm}$.

The site where the laser Doppler sensor was attached was marked carefully and was always the same for the three consecutive measurements on each infant. To determine the zero flow level and to obtain reactive hyperaemia, the vascular bed of the forehead was occluded four times, twice for $30 \mathrm{~s}$ and twice for $60 \mathrm{~s}$, during each measurement, by pressing the sensor against the skull. The pressure necessary to overcome the arterial blood pressure of the newborn infant can easily be achieved. This zero flow level determination is necessary because "biological noise", e.g. Brownian molecular movement and vessel wall movement, produce a baseline signal that has to be subtracted in analysing the data. How far skull bone perfusion increases the zero flow level is unknown. Given the thickness of the newborn's skin and the uncertain measuring depth we cannot be absolutely sure that skull bone perfusion does not contribute to an increase in zero flow level. In addition to the laser Doppler signal, the following data were recorded using a Teac MR-30 cassette recorder: skin temperature of the chest (Yellow Springs thermistor probe 409-B), heart rate and thoracic impedance respiratory waveform (Hewlett Packard 78214-A).

The behavioural state was determined by observing the infants and by independently analysing the tracings of respiration and heart rate. Active and quiet sleep were distinguished using the criteria of Prechtl [15]. Data analysis: laser Doppler flow was measured in arbitrary units (au) above zero flow level. Reactive hyperaemia was described by the following parameters (Fig. 1): the maximum blood flow after occlusion $\left(V_{\max }\right)$; the time taken in seconds to reach the maximum response $\left(t_{\max }\right)$; the time taken in seconds to achieve a recovery level halfway between the maximum and preocclusive levels $\left(t_{1 / 2}\right)$. Furthermore, we calculated the percentage increase in skin blood flow above preocclusive level (overshoot).

All data recorded on tape were fed into a personal computer at a sample frequency of $10 \mathrm{~Hz}$. For statistical analysis the $t$-test for paired samples was used. The difference in average flow values were considered significant if the $P$ value was less than 0.05 . 


\section{Results}

A representative recording of forehead skin blood flow, respiration, heart rate and skin temperature, including a postocclusive reactive hyperaemia, is shown in Fig. 1.

The baseline forehead skin blood flow was found to decrease significantly during the first 5 days, in active as well as in quiet sleep. During active sleep, the flow decreased from $29.3 \pm 11.7$ au to $17.6 \pm 7.1$ au. During quiet sleep, the flow decreased from $23.5 \pm 11.7$ au to $13.9 \pm 7.9 \mathrm{au}$. The average decrease in skin blood flow was $29.4 \%$ and $25.9 \%$ for active and quiet sleep, respectively $(P<0.01)$ (Fig. 2).

No significant differences could be found between the reactive hyperaemia parameters recorded after 30 and $60 \mathrm{~s}$ occlusion and therefore the results were combined. The time taken to reach maximum flow after occlusion $\left(t_{\max }\right)$ increased during the
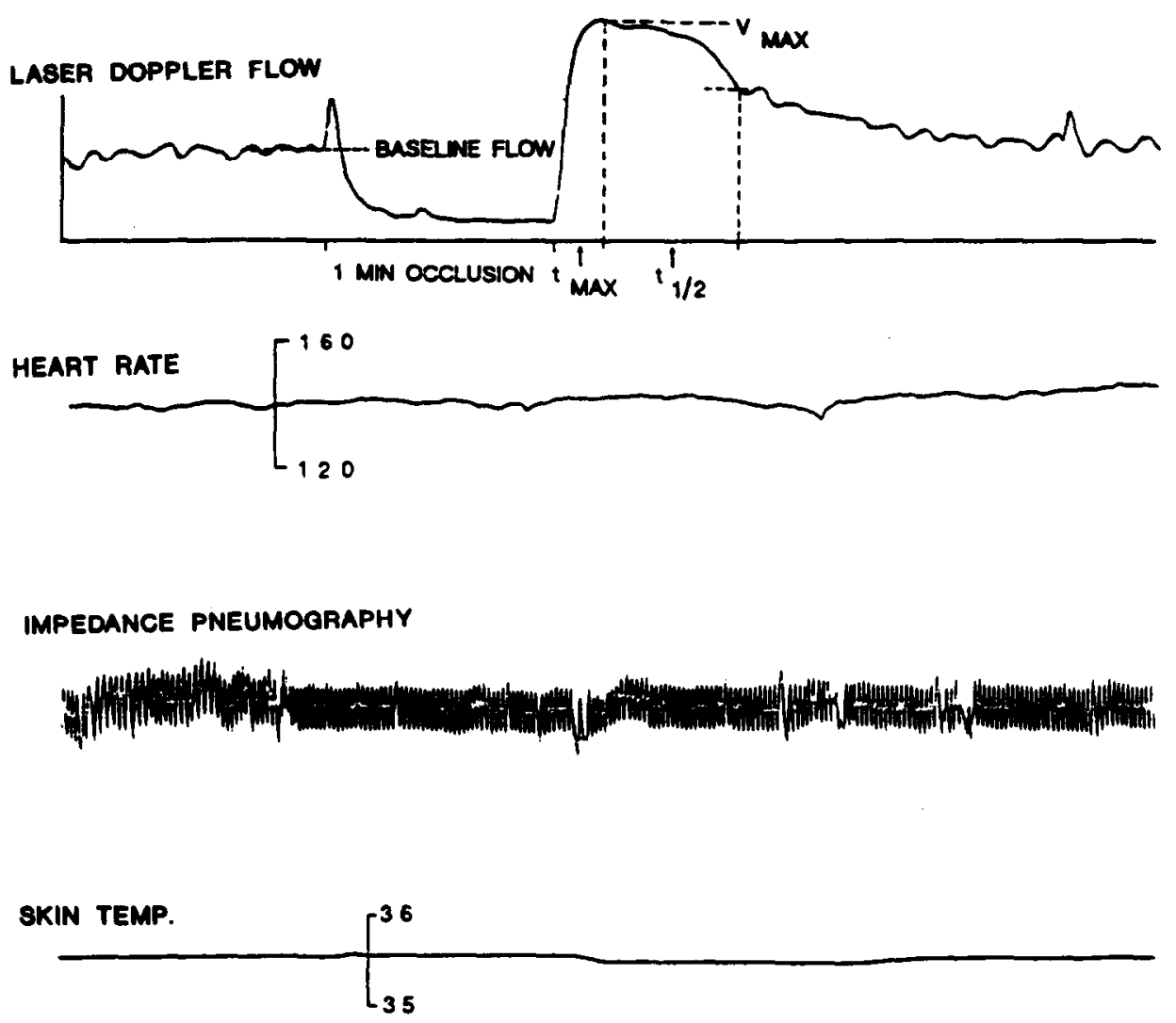

Fig. 1. Representative recording of skin blood flow, including reactive hyperaemia after $1 \mathrm{~min}$ of occlusion. Heart rate, respiration and skin temperature are also presented. $v_{\max }$, maximum blood flow after occlusion; $t_{\max }$, time taken to reach maximum response; $t_{1 / 2}$, half-time recovery. 


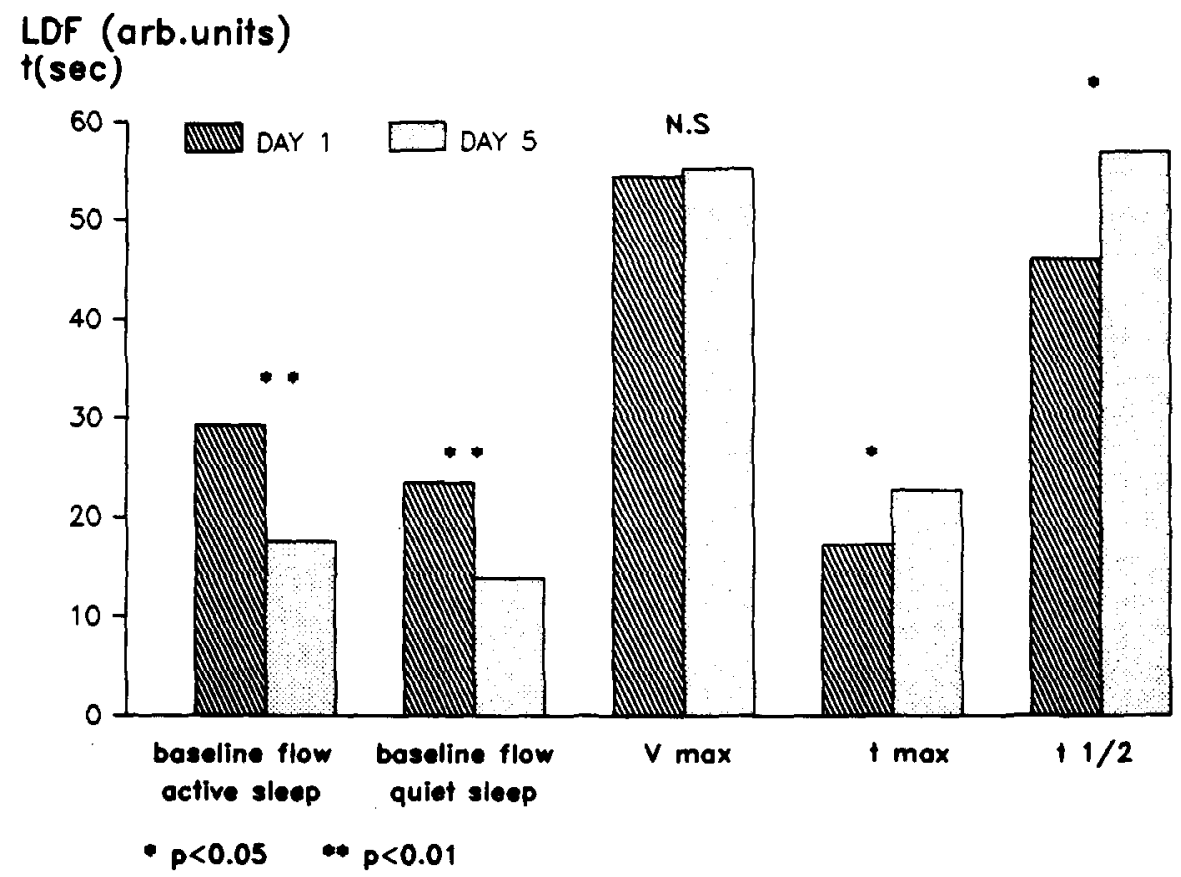

Fig. 2. Histogram showing the differences in baseline skin blood flow and reactive hyperaemia parameters on day 1 and on day 5 .

\section{LDF (arbitrary units)}

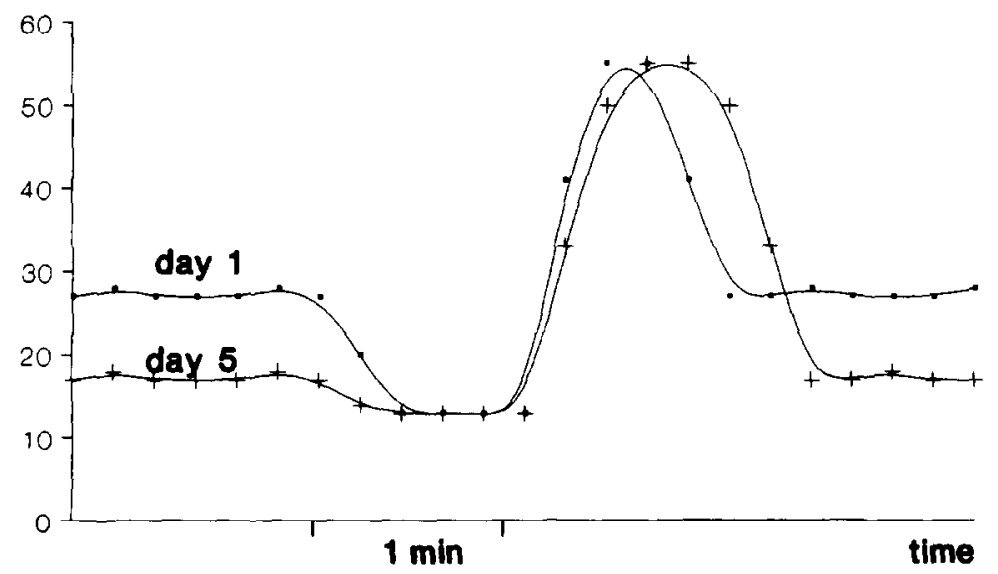

Fig. 3. Induced reactive hyperaemia on day 1 and on day 5 , showing the most relevant differences in skin blood flow. 
first 5 days from $17.3 \pm 6.9 \mathrm{~s}$ to $22.7 \pm 7.7 \mathrm{~s}$ (mean \pm S.D.), the average increase was $24 \%$ (Fig. 2). The halftime recovery $\left(t_{1 / 2}\right)$ increased in the first 5 days from 46.1 $\pm 10.2 \mathrm{~s}$ to $64.5 \pm 17.4 \mathrm{~s}$ (mean \pm S.D.), with an average increase of $29 \%$ (Fig. 2). No significant changes could be found in the maximum flow during hyperaemia $\left(V_{\max }\right)$.

All the differences observed between day 1 and day 3 and between day 3 and day 5 were too small to reach the level of statistical significance. The variations in skin temperature were very small and did not significantly influence the skin blood flow.

The results are summarized in Fig. 3, where the mean values of reactive hyperaemia on day one and on day five are presented.

\section{Discussion}

The results of the present study indicate that changes in forehead skin blood flow do occur in the first week after birth. The baseline skin blood flow decreased significantly during the first 5 days, the average decrease being $29.4 \%$ and $25.9 \%$ for active and quiet sleep, respectively. This can be explained, at least partly, by the morphological changes in the microvessels of the skin. Just after birth, the microvascular bed of the skin consists primarily of larger vessels and a disorderly capillary network with none or very few papillary loops $[3,14,16]$. This provides a relatively small vascular exchange area. Therefore, a relatively large flow is necessary to meet the needs of nutrition and, in particular, thermoregulation after birth. In the first week after birth, enlargement of the capillary network takes place, with an increase in height and rotation of the papillary loops $[14,16]$. This results in an increase in the microvascular exchange area in the skin, in which periodic vasodilation and vasoconstriction appears (so-called vasomotion) [7]. The enlargement of the microvascular exchange area and the possibility of a more selective perfusion, leads to a more effective and, therefore, lower skin blood flow. The differences in skin blood flow found between active and quiet sleep agree with previous findings, where the skin blood flow during active sleep was increased by an average of $28 \%$, compared to skin blood flow during quiet sleep [20].

The results of the present study are in agreement with the findings of Ahlsten, who used the transcutaneous $\mathrm{PO}_{2}$ method as an indicator of skin blood flow and observed a decrease in baseline skin blood flow during the first few days of life [1]. Stromberg, who used laser Doppler flowmetry [19], also found a decrease in baseline skin blood flow during the first few hours of neonatal life. Earlier studies on this subject using venous occlusion plethysmography showed similar changes in total blood flow in the leg $[4,22]$. Norman et al. [13] described an increase in capillary blood cell velocity, measured with videometric microscopy, which seems to contradict our results. Laser Doppler flowmetry, however, measures more than just capillary blood flow. The penetration depth of most laser Doppler sensors is several millimeters $[2,5,10]$. The penetration depth of the laser Doppler used in this study is between 1.5 and $2 \mathrm{~mm}$. This implies a skin blood flow signal derived from capillaries and, in greater part, from thermoregulatory microvessels deeper in the skin. This thermoregulatory flow might be different and even bypass [13] the capillary nutritional flow. 
During the first week, the reaction of the microvascular bed to occlusion also changes (Fig. 3). The $t_{\max }$ and the $t_{1 / 2}$ both increased, by $24 \%$ and $29 \%$, respectively. During occlusion, hypoxia occurs, which induces vasodilatation through the accumulation of metabolites $[8,21]$. Because the amount of skin microvessels with a relatively large diameter dominates the few or non-existent capillary loops on the first day of life $[14,16]$, a low resistance followed by a rapid reactive hyperaemia with a short $t_{\max }$ is most likely. On day 5 , the newly formed capillaries, with a smaller diameter, produce prolonged reactive hyperaemia and an increased recovery time, represented by an increased $t_{\max }$ and $t_{1 / 2}$.

The maximal flow after occlusion did not change significantly, despite the morphological and regulatory changes in the microvascular bed. Short-term occlusion (30 or $60 \mathrm{~s}$ ) probably only causes partial reactive hyperaemia. Studies on adults [11] have revealed that an occlusion of several minutes is required for measuring the maximum skin blood flow capacity. The reactive hyperaemia occurring after 30 or $60 \mathrm{~s}$ of occlusion merely represents the vascular reaction to changes in transmural pressure and the reaction to a dilator substance [17].

We conclude that changes take place in the basal skin blood flow and in the $t_{\max }$ and the $t_{1 / 2}$ of the postocclusive reactive hyperaemia during the first 5 days after birth. This is most likely the result of morphological and regulatory changes in the microvasculature of the skin.

\section{Acknowledgements}

This study was supported by The Netherlands Technology Foundation (S.T.W.).

\section{References}

1 Ahlsten, G., Ewald, U., Kobbah, M. and Tuvemo, T. (1984): Postnatal changes in skin vascular tone recorded by transcutaneous $\mathrm{Po}_{2}$ electrode at $37^{\circ} \mathrm{C}$. Int. J. Microcirc. Clin. Exp., 3, 233 (abstr).

2 Anderson, R.R. and Parrish, J.A. (1982): Optical properties of human skin. In: Science of photomedicine, pp. 177-194. Editors: J.D. Regan and J.A. Parish. Plenum Press, New York.

3 Arajärvi, T. (1953): Microscopic investigations into the capillaries of newborn, especially premature infants. Biol. Neonat., 2, 139-158.

4 Berg, K. and Celander, O. (1971): Circulatory adaptation in the thermoregulation of full-term newborn infants. Acta Paediatr. Scand., 60, 278-284.

5 Bonner, R. and Nossal, R. (1981): Model for laser Doppler measurements of blood flow in tissue. Appl. Opt., 20, 2097-2107.

6 Celander, O. and Mårild, K. (1962): Reactive hyperaemia in the foot and calf of the newborn infant. Acta Paediatr. Scand., 51, 544-552.

7 Colantuoni, A., Bertuglia, S. and Intaglietta, M. (1984): Quantitation of rhythmic diameter changes in arterial microcirculation. Am. J. Physiol., 246, H508-517.

8 Fairchild, H.M., Ross, J. and Guyton, A.C. (1966): Failure of recovery from reactive hyperemia in the absence of oxygen. Am. J. Physiol., 210, 490-492.

9 Jentink, H. (1989): Laser Doppler Velocimetry Using Diode Lasers, pp. 59-70. Thesis, Dept. Appl. Phys., Twente University of Technology.

10 Kolari, P.J. (1985): Penetration of unfocussed laser light into the skin. Arch. Dermatol. Res, 277, $342-344$.

11 Kristensen, J.K. and Hendriksen, O. (1980): Excess cumulative blood flow and repayment during reactive hyperemia in human cutaneous tissue. Acta Physiol. Scand., 108, 1-6. 
12 Nilsson, G.E., Tenland, T. and Öberg, P.A. (1980): Evaluation of a laser Doppler flowmeter for measurement of tissue blood flow. IEEE. Trans. Biomed. Eng. BME-27, 597-604.

13 Norman, M. M., Herin, P., Fagrell, B. and Zetterström, R. (1988): Capillary blood cell velocity in fullterm infants as determined in skin by videophotometric microscopy. Pediatr. Res., 23, 585-588.

14 Perera, P., Kurban, A.K. and Ryan, T.J. (1970): The development of the cutaneous microvascular system in the newborn. Br. J. Dermatol, 82, 86-91.

15 Prechtl, H.F.R. (1974): The behavioural states of the newborn infant (a review). Brain Res., 76, 185 $-212$.

16 Schwalm, H. (1934): Die Hautkapillaren bei Neugeborenen. Arch. Kinderheilk., 103, 129-137.

17 Shepard, J.T. (1964): Reactive hyperaemia in human extremities. Circ. Res., 14, 1/76-1/79.

18 Stern, M.D., Lappe, D.L., Bowen, P.D. et al. (1977): Continuous measurement of tissue blood flow by laser Doppler spectroscopy. Am. J. Physiol., 232, 441-448.

19 Strömberg, B., Riesenfeld, T. and Sedin, G. (1984): Laser Doppler measurement of skin blood flow in newborn infants. Int. J. Microcirc. Clin. Exp., 3, 326 (abstr).

20 Suichies, H.E., Aarnoudse, J.G., Okken, A., Jentink., H.W., de Mul, F.F.M. and Greve, J. (1987): Forehead skin blood flow in normal neonates during active and quiet sleep, measured with a diode laser Doppler instrument. Acta Paediatr. Scand., 77, 22-225.

21 Tenland, T. (1982): On Laser Doppler Flowmetry. Methods and Microvascular Applications, pp. 1 -19. Thesis, Dept. of Biomedical Engineering, Linköping University.

22 Wu, P.Y.K. (1980): Peripheral blood flow in the neonate. I. Changes in total, skin and muscle blood flow with gestational and postnatal age. Pediatr. Res., 14, 1374-1378.

23 Wunderlich, R.W., Folger, R.L., Giddon, D.B. and Ware, B.R. (1980): Laser Doppler blood flow meter and optical plethysmograph. Rev. Sci. Instrum., 51 (9), 1258-1262. 